\title{
ISABEL DE FARNESIO Y LA COLECCIÓN REAL ESPAÑOLA DE ESCULTURA. DISTINTAS NOTICIAS SOBRE COMPRAS, REGALOS, RESTAURACIONES Y EL ENCARGO DEL “CUADERNO DE AIELLO”*
}

\author{
POR \\ MERCEDES SIMAL LÓPEZ \\ Universidad Complutense de Madrid \\ Becaria FPI
}

\begin{abstract}
El presente trabajo aporta nuevos datos respecto al gusto de Felipe V e Isabel de Farnesio hacia la escultura y las antigüedades, así como sobre la procedencia e identificación de las obras que componían su colección.

Además, precisa las fechas en las que se realizó la descripción de la galería de estatuas instalada en el palacio real de San Ildefonso y de las láminas que componen el "Cuaderno de Aiello" entre 1750 y 1751, así como los motivos por los que el proyecto fue realizado y las causas por las que finalmente la propia Isabel de Farnesio decidió evitar que fuera publicado. Asimismo aporta datos relativos a las restauraciones a que fueron sometidas las esculturas que se conservan en la actualidad en las colecciones del Patrimonio Nacional y del Museo Nacional del Prado.

Palabras clave: Felipe V; Isabel de Farnesio; Eutichio de Aiello; escultura; antigüedades, restauración; La Granja de San Ildefonso; Bernini; Cristina de Suecia; Marqués del Carpio; Cardenal Belluga; Roma; Parma; Colorno; Aranjuez; Museo del Prado.
\end{abstract}

This study contributes new facts concerning the taste of Felipe V and Isabel de Farnesio for sculpture and antiquities, as well as the provenance and identification of the works composing their collection. Moreover, the dates in which the description of the gallery of statues installed in the Royal Palace of San Ildefonso was carried out have been determined, as have been those of the plates which make up the "Aiello Notebook" between 1750 and 1751. The motives for carrying out this project and the reasons Isabel de Farnesio finally decided not to publish it are also examined. Data relating to conservation work carried out on these sculptures, now preserved in the collections of Patrimonio Nacional and the Museo del Prado, are likewise included.

Key words: Felipe V; Isabel de Farnesio; sculpture; Eutichio Aiello; antiquities; restoration; La Granja de San Ildefonso; Bernini; Cristina de Suecia; Marqués del Carpio; Cardenal Belluga; Rome; Parma; Colorno; Aranjuez; Museo del Prado.

* El presente trabajo ha sido realizado durante el disfrute de una beca de Formación de Personal Investigador de la Comunidad de Madrid, financiada por la Consejería de Educación de la Comunidad de Madrid y el Fondo Social Europeo.

Quiero agradecer a Delfín Rodríguez Ruiz, José María Luzón, Jacobo Storch de Gracia, Helena Pérez y Pilar Silva la ayuda y el apoyo que me han prestado para la realización de este trabajo, continuación de las investigaciones que 
"Es sin disputa ley de raza y de familia de una princesa italiana, y Farnesio, cuya Casa lleva vinculada la gloria de haber restituido a la cultura europea tantas obras maestras de la estatuaria antigua -el famoso Toro, la Flora, el Hércules, el Gladiador- la que la obliga a mirar con veneración (noblesse oblige) el arte clásico de la bella Italia [...] y vuelve, muerto su esposo, a las tradiciones de familia, e identificando su nombre con el de la ilustre Cristina de Suecia, saca de sus escondrijos la magnífica colección de mármoles antiguos que allegó esta reina; dispone para ella suntuosos salones en el piso bajo del Palacio de San Ildefonso, y hace de la selecta y numerosa gliptoteca el recreo de su viudez, durante los trece años que en aquel solitario Edén vive recluida, acompañada de su hijo el cardenal arzobispo de Toledo, hasta que la razón de Estado la obliga a abandonarlo para restituirse a Madrid, al fallecer su entenado Fernando VI"

Con estas palabras definió Pedro de Madrazo el gusto de Isabel de Farnesio por la escultura antigua y la labor que llevó a cabo en relación con la colección de estatuas de la reina sueca, adquirida por los monarcas españoles en 1724 por decisión de la soberana.

Nacida en Parma el 25 de octubre de 1692, hija de Odoardo Farnesio y Dorotea Sofía de Neoburgo, Isabel tuvo un destino similar al de Cristina de Suecia, ya que al igual que ésta perdió a su padre durante su infancia, cuando tan sólo tenía un año, y pasó a ser en 1731, al fallecer sin sucesión Antonio Farnesio, octavo titular de la Casa, la heredera de los ducados de Parma, Piacenza y Guastalla, y del gran ducado de Toscana ${ }^{2}$.

Su educación en la corte farnesiana corrió a cargo de su padrastro y tío Francisco, VII duque de Parma desde 1694 y casado con Dorotea Sofía en 1695. Bajo su tutela, Isabel recibió una completa formación que le permitió hablar y escribir varias lenguas -italiano, latín, alemán, francés y, desde 1714, español-, estudiar retórica, filosofía, geografía, astronomía e historia, y desarrollar un gran interés por la música, la literatura y la pintura ${ }^{3}$. A su preparación en el campo de las bellas artes también contribuyeron los conocimientos que le proporcionaron los ricos fondos de la colección artística familiar, la mayoría de cuyas obras se encontraban durante la juventud de Isabel de Farnesio repartidas entre los palacios que Farnesio poseía en Parma, Piacenza y Colorno ${ }^{4}$.

comenzaron en 1999 con motivo de la exposición El Real Sitio de San Ildefonso. Retrato y escena del Rey [Madrid, 2000]. Asimismo quiero agradecer a Rafael Villareal, Isabel Garzón y Manuel Jaime, del Archivo General de Palacio, y a Isabel Aguirre, y Julia Rodríguez de Diego, del Archivo General de Simancas, su amabilidad y ayuda durante la consulta de sus respectivos archivos.

Listado de abreviaturas: A.G.P.: Archivo General de Palacio [B.R.: Administraciones Patrimoniales, Buen Retiro; S.I.: Administraciones Patrimoniales, San Ildefonso]; A.G.S.: Archivo General de Simancas; A.H.N.: Archivo Histórico Nacional; A.M.J.: Archivo del Ministerio de Justicia; A.M.P.: Archivo del Museo del Prado; A.S.F.: Archivo de la Real Academia de Bellas Artes de San Fernando; A.S.N.: Archivio di Stato di Napoli; A.S.P.: Archivio di Stato di Parma; B.A.V.: Biblioteca Apostolica Vaticana; B.N.M.: Biblioteca Nacional de Madrid; M.A.E.: Archivo del Ministerio de Asuntos Exteriores, Madrid; M.P.: Museo Nacional del Prado; P.N.: Patrimonio Nacional.

1 Madrazo, P. de, Viaje artístico de tres siglos de las colecciones de cuadros de los Reyes de España, Barcelona, 1884, pp. 192-193

2 Mafrici, M., Fascino e Potere di una Regina. Elisabetta Farnese sulla scena europea (1715-1759), Roma, 1999; Pérez Samper, M. A., Isabel de Farnesio, Barcelona, 2003. Sobre la coyuntura histórica que convirtió a Isabel en heredera del ducado farnesiano, siguen siendo fundamentales los estudios de Drei, G., I Farnese. Grandezza e decadenza di una dinastia italiana, Roma, 1954, pp. 247-295, y Nasalli Rocca, E., I Farnese, Varese, 1969, pp. $209-251$.

3 Lavalle Cobo, T., "Isabel de Farnesio, la pasión por el arte", en La mujer en el arte español, Madrid, 1997, pp. 217-228; Ídem, "Biografía artística de Isabel de Farnesio”, en Rodríguez Ruiz, D. (com.), El Real Sitio de San Ildefonso. Retrato y escena del Rey, Madrid, 2000, pp. 182-193; Bertini, G., "La formación cultural y la educación artística de Isabel de Farnesio en la corte de Parma”, en Morán Turina, J. M. (com.), El arte en la corte de Felipe V, Madrid, 2002, pp. 417-433, en especial pp. 424-425.

4 Sobre la evolución del coleccionismo farnesiano, Bertini, G., La galleria del duca di Parma, Bolonia, 1987, pp. 31-36; Denunzio, A. E., "Il collezionismo farnesiano a Parma e una analisi ravvicinata dell'inventario dei quadri del 
Tras contraer matrimonio con Felipe V en 1714, poco a poco la reina, que compartía todas las aficiones del monarca - desde la caza al gusto por la pintura y el dibujo ${ }^{5}$ - fue haciéndose con la dirección artística de la corte hispana. El gusto italiano fue imponiéndose paulatinamente gracias a la contratación de artistas de esta nacionalidad, frente a la "corriente" francesa que había dominado hasta entonces desde la llegada del Borbón a España en 1700.

Primero bajo la dirección del ministro Alberoni ${ }^{6}$ y a partir de 1719 de la de Andrea Procaccini, pintor romano formado en el taller de Carlo Maratti, Príncipe de la Academia de San Lucas y miembro de la Arcadia, cuyo estilo de vida "más parecía el de un caballero que el de un pintor"7, Isabel de Farnesio procedió a la remodelación de los distintos reales sitios y la adquisición de obras de arte que completasen los fondos de la colección real ${ }^{8}$.

Una de las piezas clave de la decoración del palacio de San Ildefonso ${ }^{9}$, concebido inicialmente para el retiro de los monarcas, fue la colección de esculturas perteneciente a la reina Cristina de Suecia ${ }^{10}$. Con su adquisición en 1724, Felipe V y especialmente Isabel de Farnesio, verdadera responsable de la compra ${ }^{1}$, vieron culminados sus deseos de hacerse con una de las más prestigiosas

1680", Aurea Parma, 1993, Vol. II, pp. 93-127; Fornari Schianchi, L., "Venite all'ombra dei gran giglio d'oro": forme del collezionismo farnesiano a Parma", en Fornari Schianchi, L. y Spinosa, N. (com.), I Farnese. Arte e Collezionismo, Milán, 1995, pp. 72-75; Mambriani, C., "Dalla corte alla città: le trasformazioni della Pilotta dagli ultimi Farnese ad oggi”, en Fornarl Schianchi, L. (dir.), Il Palazzo della Pilotta a Parma. Dai servizi della corte alle moderne istituzioni culturali, Milán, 1996, pp. 38-40.

5 Salazar y Castro, L., Índice de las glorias de la Casa Farnese o resumen de las heroycas acciones de sus principes, que consagra a la augusta reyna de las Españas Doña Isabel Farnese (1715), Madrid, 1997, Vol. II, p. 536.

6 Tan sólo citar a modo de ejemplo la satisfacción que sintieron los reyes al contemplar en el alcázar de Madrid "il grande Appartamento, con ornamenti di stuchi, marmi e intaglii dorati, in mezzo a quali sono le pareti coperte d'insigni quadri di Tiziano, e d'altri piu celebri Pit[to ${ }^{\text {ri }}$ nella mag[gio ${ }^{\mathrm{r}}$ parte italiani, de passati secoli levate si degne piture dall' abbandono in cui giacevano da longo tempo, il tutto ideatto dal $\operatorname{Sig}^{r}$ Cardinale Alberoni, che ha reso il Palazzo de Rè Cattolici un vero allog[gi] ${ }^{\circ}$, e stanza da monarca". Carta de Annibale Scotti al duque de Parma, Madrid, 27 noviembre 1719. A.S.N., Archivio Farnesiano, fascio 55, fol. 391 r y v.

7 Haskell, F., Patronos y pintores. Arte y sociedad en la Italia barroca, Madrid, 1984, p. 35, nota 68. Sobre su estancia en España, Rius Serra, J., "La ida de Procaccini a España", Archivo Español de Arte, núm. 32, pp. 218-222; LavalleCobo, T., "La obra de Andrea Procaccini en España", Academia, núm. 73, 1991, pp. 381-398; Rodríguez Ruiz, D., "El Palacio del Real Sitio de La Granja de San Ildefonso. Un retrato cambiante del rey", en Rodríguez Ruiz, D. (com.), ob. cit., 2000(a), pp. 25-41; Ídem, "El Palacio del Real Sitio de La Granja de San Ildefonso. ¿Un espacio para la teoría de la Arquitectura?", Reales Sitios, núm. 144, 2000(b), pp. 2-13.

8 Sobre la compra de la colección de pinturas de Carlo Marattí, Mena Marqués, M. B., "La colección de pintura de Carlo Maratti”, en Rodríguez Ruiz, D. (com.), ob. cit., 2000, pp. 194-202, que recoge la bibliografía sobre el tema. Respecto a la participación de la reina en el trabajo de Procaccini, García, L. y Pelizzoni, L., "La construcción del palacio de La Granja a través del epistolario entre Dorotea Sofía de Neoburgo e Isabel de Farnesio: Andrea Procaccini y el modelo parmense de edilicia de jardines", en El Mediterráneo y el Arte Español. Actas del XI congreso del CEHA (Valencia, 1996), Valencia, 1998, pp. 183).

9 Sobre la evolución del palacio durante el reinado de Felipe $\mathrm{V}$ véanse los distintos estudios recogidos en Rodríguez Ruiz, D. (com.), ob. cit., 2000; Rodríguez Ruiz, D., ob. cit., 2000(b); Sancho Gaspar, J. L., "El retiro de Felipe V: imagen y sentido del Palacio de La Granja en 1724", Reales Sitios, núm. 150, 2001, pp. 37-50.

10 Boyer, F., "Les antiques de Christine de Suède Rome", Revue Archéologique, 1932, pp. 254-267; Borsellino, E., "Cristina di Svezia collezionista", Ricerche di Storia dell'Arte, núm. 54, 1994, pp. 4-52; Elvira Barba, M. A. (com.), Cristina de Suecia en el Museo del Prado. Madrid, 1997; Montanari, T., "La dispersione delle collezioni di Cristina di Svezia. Gli Azzolini, gli Ottoboni e gli Odescalchi”, Storia dell’Arte, núm. 90, 1997, pp. 250-300; Coppel Aréizaga, R., "Relieves que decoran los pedestales de las esculturas de la Reina Cristina de Suecia", Archivo Español de arte, núm. 279, 1997, pp. 310-315; Luzón Nogué, J. M., "La colección de esculturas de Cristina de Suecia y su traslado a España", España y Suecia en la época del barroco. Madrid, 1998, pp. 897-922.

11 Respecto al proceso de compra de la colección de Cristina de Suecia por los monarcas españoles, P. F., "Nota delle casse che gli 2 di marzo de 1725 devono esser imbarcate", Revista de Archivos, Bibliotecas y Museos, 1876, pp. 163164 y 180-181; Salas, X. de, "Compra para España de la colección de antigüedades de Cristina de Suecia”, Archivo Español 
colecciones de estatuas de la Europa del momento, consiguiendo cubrir la carencia de antigüedades de prestigio -elemento fundamental para la expresión de la magnificencia del monarca en la política de representación de la época- de la que adolecía la colección real española, y de la que hasta entonces la reina se había lamentado ${ }^{12}$.

La importancia de la colección reunida por Cristina de Suecia debía de ser bien conocida por Isabel de Farnesio, tanto por la excelente calidad de las esculturas como por el "conocimiento" personal que la parmesana debía tener de la reina sueca. Además de ser un personaje vinculado con la historia de la familia Farnesio - poco antes de su llegada a la Ciudad Santa Ranuccio II recibió a Cristina de Suecia en Caprarola en 1655 y en 1656 el duque le cedió el palacio Farnesio en Roma, en donde la reina instaló su residencia durante siete meses-, la soberana era una figura por la que Isabel sintió un especial interés, como demuestra el contenido de su biblioteca. Repartida entre los palacios de La Granja y del Buen Retiro ${ }^{13}$, contenía ejemplares de los principales libros publicados sobre antigüedades, algunos de ellos editados bajo su protección como las Stampe degli avanzi dell 'antica Roma de Overbeek ${ }^{14}$ o el cuarto volumen Delle magnificenze di Roma antica e moderna de Giuseppe Vasi, así como una biografía de Cristina de Suecia y tres volúmenes de su correspondencia. Además, el gusto de Isabel de Farnesio hacia las antigüedades la hizo mantenerse informada de los distintos descubrimientos arqueológicos que se produjeron en 1725 en las excavaciones de los Orti Farnesiani del Palatino, y años más tarde en la redescubierta ciudad de Herculano ${ }^{15}$.

Felipe V tampoco era ajeno a estos gustos. Además del conocimiento que tenía de las colecciones de antigüedades reunidas por Luis XIV, en la que figuraban vaciados de esculturas de la colección de Cristina de Suecia como el grupo de Cástor y Pólux o la Venus en cuclillas ${ }^{16}$, durante su viaje a Italia en 1702 en Nápoles el Nuncio Pontificio eligió significativamente como regalo para el nieto del "Rey Sol" varias esculturas, entre ellas un Hércules de Bernini ${ }^{17}$, mientras que

de Arte, 1940-41, pp. 242-246; Luzón Nogué, J. M., "Isabel de Farnesio y la Galería de Esculturas de San Ildefonso", en Rodríguez Ruiz, D. (com.), ob. cit, 2000, pp. 206-212; Riaza de los Mozos, M., y Simal López, M., "La Statua è un prodigio dell'arte": Isabel de Farnesio y la colección de Cristina de Suecia en La Granja de San Ildefonso", Reales Sitios, núm. 144,2000 , pp. 56-67.

12 El 18 de septiembre de 1722 Isabel de Farnesio agradecía por carta a su madre la descripción que le había proporcionado del jardín de Colorno, "che sarà molto più bello che il nostro quanto non vi fosse altro che le statue antiche, che non habiamo noi" (A.S.P., Casa e Corte Farnesiana, busta 41, fasc. 7, citada en Bertini, G., ob. cit., 2002, p. 433, nota 96).

13 Santiago Páez, E., "La biblioteca de Isabel de Farnesio", en Santiago Páez, E. (dir.), La Real Biblioteca Pública, 1711-1760. De Felipe V a Fernando VI, Madrid, 2004, pp. 269-284.

14 B.N.M., ER-2026. Reeditado por Jacopo Amigoni en Londres en 1739, está significativamente dedicado a Isabel de Farnesio probablemente con la intención de agradar a la reina y poder trasladarse a la corte española, como finalmente sucedió en 1747. Scarpa Sonino, A., Jacopo Amigoni, Soncino, 1994, pp. 39-42; Santiago Páez, E., ob. cit., p. 275.

15 Sobre las excavaciones llevadas a cabo en la colina del Palatino en Roma, propiedad de los Farnesio, se conservan distintas cartas fechadas en 1726 en las que el duque de Parma informaba a su embajador en la corte española, el marqués de Scotti, del hallazgo de dos "insigni statue" de basalto que fueron inmediatamente trasladadas a Colorno -actualmente en la Galleria Nazionale de Parma-, para las que necesitaba cierta cantidad de dicha piedra para proceder a su restauración, por lo que le enviaba una pequeña muestra (12 de julio de 1726, A.S.N., Archivio Farnesiano, fascio 65, fols. 545v-547). Scotti, tras buscar materiales iguales en canteras de Granada, Osuna, Zaragoza y el Paular, envió tres muestras muy similares al duque ( 7 de septiembre de 1726, Idem, fols 976r y v). Sobre el conocimiento que los reyes tenían de las excavaciones de Herculano, véase nota 24

16 Haskell, F. y Penny, N., El gusto y el arte de la Antigüedad. El atractivo de la escultura clásica (1500-1900), Madrid, 1990, pp. 54-59.

17 El encuentro entre ambos tuvo lugar el 30 de abril de 1702; Visconti, P. E. (ed.), Descrizione della solenne legazione del Cardinale Carlo Barberini a Filippo V (1702), reed. Roma, 1858, pp. 60-62. El legado pontificio entregó a Felipe V el regalo de Clemente XI -una reliquia de la vera cruz-, así como varios obsequios en su propio nombre. Además de un magnífico tabernáculo, una taza de ágata cubierta de piedras preciosas y cuarenta cajas que contenían valiosas hierbas aromáticas y medicinales, el cardenal obsequió al monarca con dos esculturas, una de Diana realizada en 


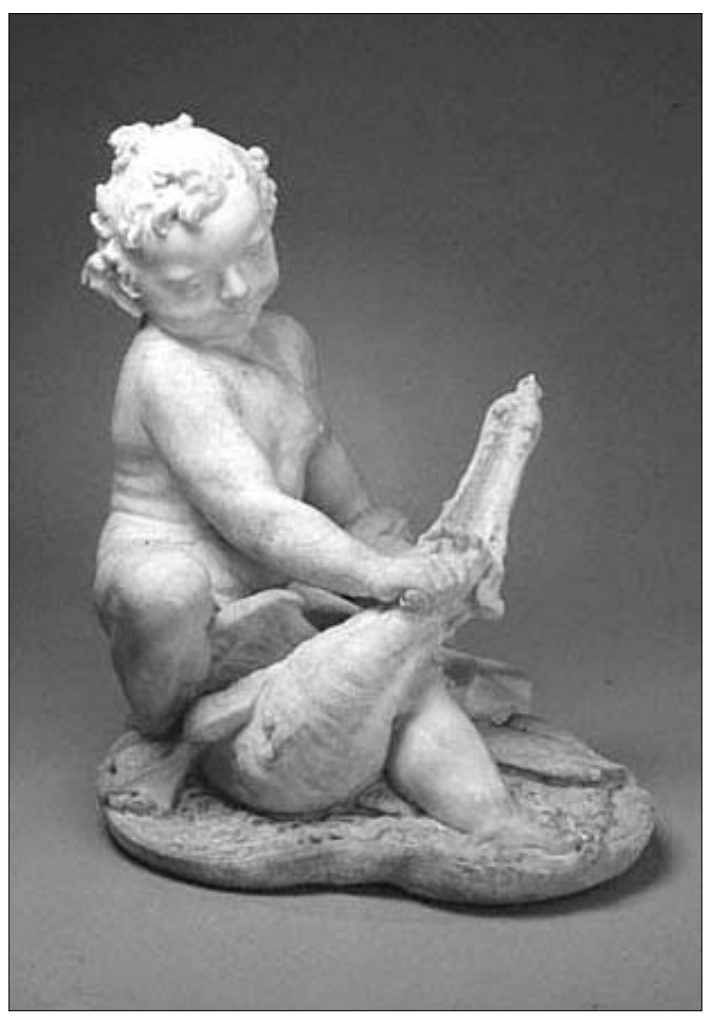

Figura 1. Gian Lorenzo Bernini, Hércules niño matando a un dragón, c. 1617.

Mármol (56x52x41,5 cm.) J. Paul Getty Museum.

en Milán Felipe V acudió a visitar la Biblioteca Ambrosiana, definida por el cronista del viaje regio como de enorme interés tanto por su fondo bibliográfico como por la galería de estatuas y vaciados y la colección de pinturas de excelentes maestros que atesoraba ${ }^{18}$.

Asimismo, en los primeros años de reinado, por orden del Borbón se instalaron galerías de escultura en los jardines del Buen Retiro ${ }^{19}$ y del Alcázar, en este último caso con las piezas confiscadas

mármoles de colores y otra de Hércules "scolpita in finissimo marmo bianco similmente d'un sol pezzo, per mano del Bernini", definida por otras fuentes como "un ercole bambino seduto sopra un drago in atto di squarciargli la gola, opera del celebratissimo Cavalier Bernini” (B.A.V., Vaticani Latini 10227, fol. 53v). Las esculturas, al igual que la mayoría de los otros regalos, procedían de la colección personal de Carlo Barberini (Lavin, M., Seventeenth-Century Barberini Documents and Inventories of Art, Nueva York, 1975, p. 445, asiento 454). No tenemos constancia de que fueran trasladadas a España, y no figuran en los distintos inventarios reales conservados. Desde 1987 el Hércules forma parte de las colecciones del J. Paul Getty Museum (Fogelman, P.; Fusco, P. y Cambareri, M., Italian and Spanish Sculpture. Catalogue of the J. Paul Getty Museum collection, Los Angeles, 2003, pp. 162-169). Agradezco a Almudena Pérez de Tudela la noticia de su ubicación actual. Sobre la presencia de obras de Bernini en la corte española, Rodríguez Ruiz, D., "Sobre el modelo de bronce de la Fontana dei Quattro Fiumi de Gian Lorenzo Bernini conservada en el Palacio Real de Madrid", Reales Sitios, núm. 155, 2003, pp. 26-41.

18 Bulifon, A., Giornale del viaggio d'Italia dell'invittissimo, e gloriosissimo Monarca Filippo V..., Nápoles, 1703, pp. $171-172$ y 344 .

19 La galería de estatuas, consistente en una sucesión de bustos sobre pedestales entre las ermitas de San Isidro y San Bruno y el jardín de las ocho calles, ya estaba configurada en enero de 1708 (A.G.P. B.R., caja 11.731, exp. 52, apartados 19 y 26) y fue respetada durante las obras de excavación y nivelación de los terrenos del jardín del Real Sitio en 1716 (A.G.P., B.R., caja 11.737, exp. 10). 
al XI almirante de Castilla ${ }^{20}$, y en la Real Biblioteca, inaugurada en 1712, el monarca ordenó reunir los distintos "bustos, estatuas ecuestres, atletas i otros primores" de bronce de pequeño tamaño que hasta entonces se encontraban dispersos por los distintos palacios reales ${ }^{21}$.

Algunos de los hijos de los monarcas también sintieron un gran interés hacia la escultura y las antigüedades. Tanto el infante don Carlos, rey de Nápoles y Sicilia y posteriormente de España, como don Felipe, duque de Parma, ambos miembros de la Academia de la Arcadia ${ }^{22}$, heredaron estas inquietudes fundando respectivamente los museos arqueológicos de Portici y Parma durante su gobierno en Italia como complemento a los proyectos de excavaciones arqueológicas que llevaron a cabo en Herculano y Veleia respectivamente ${ }^{23}$. En el caso de don Carlos, éste además les mantenía perfectamente informados de los avances de las excavaciones enviándoles planos, dibujos y libros con estampas para que los monarcas se hicieran una idea más fiel de los hallazgos que se estaban produciendo ${ }^{24}$, así como de los planes que tenía para la colección de antigüedades de la familia Farnesio 25 , de la que en diciembre de 1741, y por consejo de sus padres, cedió el "pavimento de piedras, que representa la antigua Roma" al Papa, quien deseaba instalarlo en el Campidoglio 26.

${ }^{20}$ Los bienes del almirante fueron incautados en 1707 debido al apoyo que prestó al archiduque durante la guerra de Sucesión. La galería estaba compuesta por un total de cincuenta esculturas y los gastos de traslado y montaje de las obras en el jardín de la Reina del alcázar en 1709 ascendieron a 7.333 reales de vellón (A.G.S., Dirección General del Tesoro, inventario 24, leg. 841, fols. 194-201). Asimismo también se tomaron de la colección del almirante para la decoración de los interiores del Buen Retiro "doce estatuas de mármol blanco medianas de medios cuerpos” y "dos cavezas de mármol blanco de Génoba con sus plintos", colocadas "enzima de bufetes en el palacio" (A.G.P., Administrativa, leg. 773, fol. 91 r y v).

21 Mañueco Santurtún, M. C., "Colecciones reales en el Museo Arqueológico Nacional”, en De gabinete a Museo. Tres siglos de Historia, Madrid, 1993, pp. 189-217; Idem, "El gabinete de antigüedades y el museo de monedas de la Real Librería (1711-1759), en Santiago Páez, E. (dir.), La Real Biblioteca Pública, 1711-1760. De Felipe V a Fernando VI, Madrid, 2004, pp.300-314.

22 Carlos VII de Nápoles y Sicilia fue aclamado arcade el 1 de agosto de 1748 con el nombre de "Eraclide Samio" y su hermano don Felipe, duque de Parma, quien inauguró en la capital del ducado la "delegación" local de la Academia en 1739, ingresó con el de "Leontide Eucleio". Del mismo modo, sus respectivas mujeres e hijos también fueron miembros de la Academia. Giorgetti Vichi, A. M., Gli arcadi dal 1690 al 1800, Onomasticon, Roma, 1977; Felici, L., "Relazioni fra l'Arcadia di Roma e la colonia Parmense", en Atti del convegno sul Settecento parmense nel $2^{\circ}$ centenario della morte di C. I. Frugoni, Parma, 1969, pp. 177-191.

23 Marini Calvani, M., "Dal Ducale Museo d'Antichità al Museo Archeologico Nazionale”, en Fornari Schianchi, L. (dir.), Il Palazzo della Pilotta a Parma. Dai servizi della corte alle moderne istituzioni culturali, Milán, 1996, pp. 209212. Respecto al interés de Carlos VII de Nápoles hacia las antigüedades, Fernández Murga, F., Carlos III y el descubrimiento de Herculano, Pompeya y Estabia, Salamanca, 1989; Alonso Rodríguez, M. C., "La colección de antigüedades comprada por Camillo Paderni en Roma para el rey Carlos III", en AA.VV., Illuminismo e Ilustración. Le antichità e i loro protagonisti in Spagna e in Italia nel XVIII secolo, Roma, 2003, pp. 29-45.

24 El 16 de junio de 1739 el marqués de Salas enviaba al de Villarias un plano "en que se demuestra la planta de un theatro antiguo, que se ha descubierto debajo de tierra en las inmediaciones de la villa de Portici" para que lo entregara a Felipe V e Isabel de Farnesio "como una demostración digna de sus observaciones, y de su r[ea] $]^{1}$ curiosidad y con ella se entenderan mas facil ${ }^{\mathrm{m}[\mathrm{en}] \mathrm{te}}$ las relaz ${ }^{[i o] n e s}$ que remito adj [un]tas $[. .$.$] de lo que se ha encontrado, y se ha ido sacando$ de sus excavaciones" (A.G.S., Estado, leg. 5.825, fol. 138). Meses más tarde don Carlos envió a sus padres a través de Salas los dibujos de un medallón de mármol hallado en Herculano para que se hicieran "una idea del gusto de los artes [sic] en aquel tiempo" (A.G.S., Estado, leg. 5.826, fol. 3., Nápoles, 1 de septiembre de 1739), e incluso un diario de las excavaciones de Herculano en el que se enumeraban los descubrimientos que se produjeron entre los meses de mayo y octubre de 1739 (Idem, fol. 130, Nápoles, 17 de noviembre de 1739).

25 Bertini, G., "Isabel de Farnesio y el traslado de las colecciones farnesianas de Parma a Nápoles", en El arte en la corte de los primeros Borbones (Actas congreso celebrado en la Real Sociedad Económica Matritense, enero 2003), (en prensa).

26 Inicialmente Carlos VII de Nápoles no quería desprenderse del mapa pétreo de Roma que se conservaba en el palacio Farnesio de Roma, pero finalmente accedió por las leyes que impedían la extracción de antigüedades de la ciudad, que hacían prácticamente imposible que pudiera ser trasladado a uno de sus palacios napolitanos, tal y como era su deseo. En la correspondencia al respecto se recuerda cómo en tiempos del duque Francisco "quando se llevaron a Colorno los dos colosos de Hercules y Baco, hallados en las excavaciones del Campo Vaccino, se huvieron de regalar al 
Además de la compra de la colección de Cristina de Suecia en 1724, durante su reinado Felipe $\mathrm{V}$ también adquirió en 1728 el conjunto de estatuas que el marqués del Carpio había reunido en Italia ${ }^{27}$. En los años sucesivos, cubiertas ya las necesidades de obras representativas con las que decorar los palacios reales, los monarcas dejaron pasar interesantes oportunidades de compra, renunciando en 1735 a adquirir la galería de estatuas de la difunta princesa del Piombino que se había puesto a la venta en Roma ${ }^{28}$.

A partir de entonces la colección real de escultura tan sólo se vio incrementada con obras heredadas por el fallecimiento de familiares ${ }^{29} \mathrm{o}$ a través de regalos recibidos por los monarcas, como el que en 1738 les hizo el cardenal Belluga, quien les envió desde Roma, "saviendo lo que Sus Mag[esta] des estiman las antiguedades de esta Corte, assi en quadros como en piedras [...] un S[an]to X[ris]pto a la columna, hechura de Miguel Angel Bonarota, y un Salvador de medio cuerpo, hechura del mismo, y otro representante Olimpia, hechura de la escuela griega, y con quatro pequeños originales, tres de ellos de Nuestra $\mathrm{S}[\mathrm{eño}]^{\mathrm{ra}}$ en varios misterios, y otro del serafico $\mathrm{P}[\mathrm{adr}]^{\mathrm{e}} \mathrm{S}[\mathrm{a}]^{\mathrm{n}}$ Fran $[\mathrm{cis}]^{\mathrm{co}}$ durmiendo" 30 .

En su faceta de coleccionista la reina Isabel ${ }^{31}$, que nunca olvidó su pertenencia a la dinastía Farnesio -como demuestra la presencia en el palacio de La Granja de distintas vistas de las residencias y feudos de la familia y de lienzos y bronces que reproducían las esculturas más famosas de la colección familiar ${ }^{32}-$, además de formar junto a su marido una importante colección de esculturas ${ }^{33}$ continuó, a

Card[ena $]^{l}$ Camarlengo algunos marmoles, y antiguedades de consideracion para empeñarle a dar licencia, o a disimular, que los dos colosos expresados se trasportasen a Colorno, respecto de la celosa prohivicion, que hay en Roma, sobre el punto de extraher antiguedades, de qualquier suerte que sean" (A.G.S., Estado, legs. 4.919, 5.833 y 5.834, en especial este último, doc. 48).

27 Cacciotti, B., "La collezione del XII marchese del Carpio tra Roma e Madrid", Bollettino d'arte, núm. 86-87, 1994, pp. 133-196. Respecto a la compra de la colección por Felipe V, Riaza de los Mozos, M. y Simal López, M., ob. cit., nota 4.

28 El cardenal Troiano Acquaviva, embajador español ante la Santa Sede, llegó incluso a enviar un inventario de la colección en venta realizado por el escultor florentino Antonio Montanti (A.G.S., Estado, leg. 4.893). Finalmente el conjunto estatuario fue adquirido por el marqués Lucatelli.

29 Tras la muerte de Dorotea Sofía de Neoburgo en 1748, Isabel de Farnesio heredó distintos bienes que le fueron enviados desde Parma. Entre ellos figuraban varias esculturas de carácter religioso entre las que destacaba un Cristo de Algardi, tasado por Felipe de Castro en 1766 en 30.000 reales de vellón (A.M.J., Casa Real, caja 31, exp. 4.021, fol. 9).

30 Nombrado cardenal en 1719, Luis Antonio de Moncada y Belluga residió en Roma hasta su muerte en 1743, siendo enterrado en la iglesia de Santa Maria in Vallicella. En su testamento cedía a la familia real española distintas esculturas y reliquias que le habían sido regaladas por distintos cardenales durante sus estancias en Nápoles, pero decidió enviarlos a Madrid para asegurarse de que los monarcas y los infantes los recibían, siendo entregados en la corte el 18 de febrero de 1738 (A.G.S., Estado, leg. 4.901, citado parcialmente en Bottineau, Y., El arte cortesano en la España de Felipe V (1700-1746), Madrid, 1986, p. 398, nota 105). Los relieves del Salvador (P.N., 10006486) y Olimpia (P.N., 10040081), que ingresaron en la colección de la reina en el palacio de San Ildefonso, se conservan en su emplazamiento original. Sobre este último, Herrero Sanz, M. J., "Olimpia”, en Rodríguez Ruiz, D. (com.), ob. cit., pp. 423-424, aunque atribuye erróneamente su procedencia a la colección de Cristina de Suecia. El Cristo atado a la columna fue localizado por Margarita Estella en el Museo Arqueológico Nacional de Madrid (Estella, M., "El Cristo atado a la columna del museo Arqueológico atribuido a Miguel Ángel", Archivo Español de Arte, núm. 217, 1982, pp. 69-75. Agradezco a esta estudiosa la noticia de su ubicación.

${ }^{31}$ Lavalle Cobo, T., Isabel de Farnesio. La reina coleccionista, Madrid, 2002.

32 Sobre las distintas "vistas farnesianas" realizadas por Gaspar van Wittel y Jan Frans van Bloemen, Battisti, E., "Juvarra a San Ildefonso", Commentari, núm. 9, 1958, pp. 292-293; Ruiz Alcón, M. T., "G. Vanvitelli”, Reales Sitios, núm. 50, 1976, pp. 45-52; Luna, J. J., “J. F. V. Bloemen”, Reales Sitios, núm. 49, 1976, pp. 65-72; Briganti, G., Gaspar van Wittel, Milán, 1997; Rodríguez Ruiz, D. (com.), ob. cit., 2000, pp. 296-301. Respecto a la presencia de las principales esculturas de la colección Farnesio en lienzos de Houasse y en pequeños bronces en los palacios de Felipe V e Isabel de Farnesio, Luna, J. J. (coord.), Miguel-Angel Houasse 1680-1730. Pintor de la Corte de Felipe V, Madrid, 1981, pp. 146-150 y Herrero Sanz, M. J., “Antonio Susini y el grupo escultórico del Toro Farnesio”, Reales Sitios, núm. 132, 1997, pp. 39-45. 


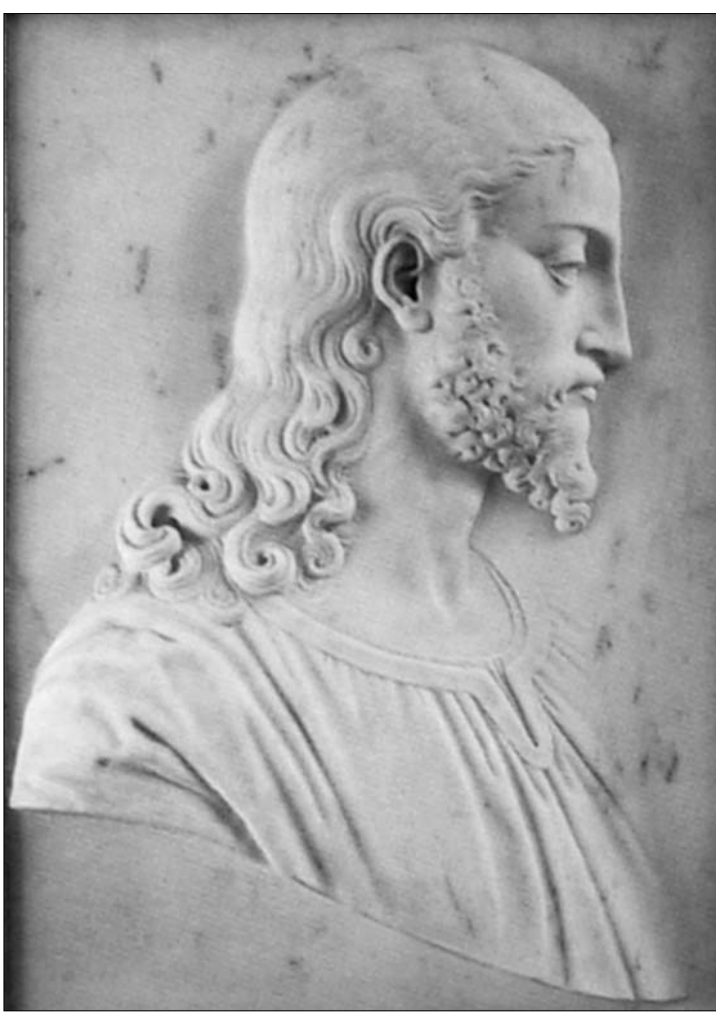

Figura 2. Anónimo italiano, Relieve del Salvador, siglo XVII. Mármol (54 x $44 \mathrm{~cm}$ ), Patrimonio Nacional, Palacio Real de La Granja de San Ildefonso.

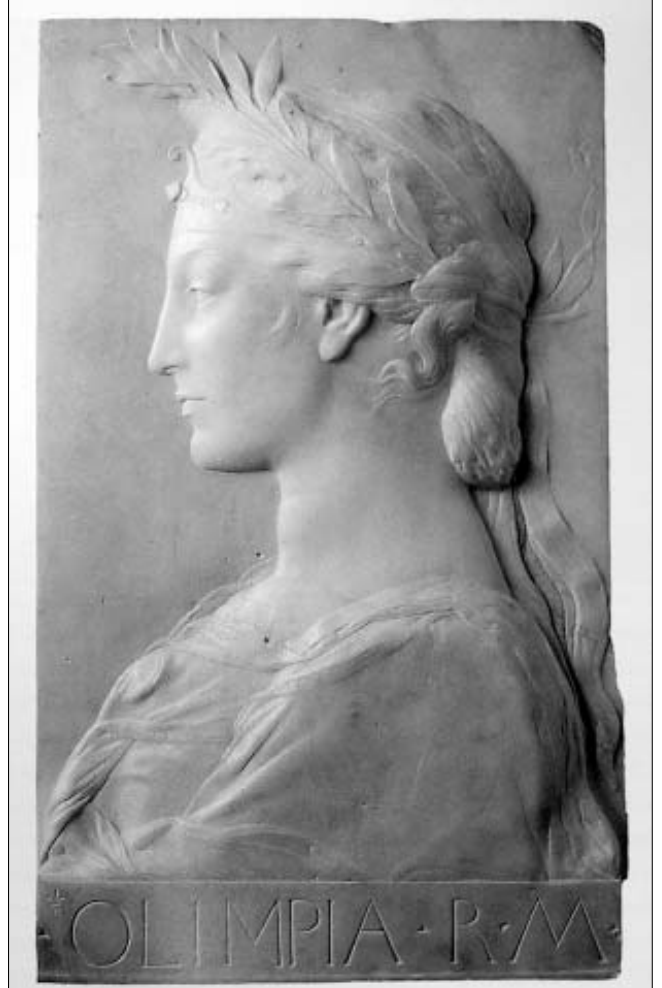

Figura 3. Anónimo italiano, Relieve de Olimpia, último cuarto siglo XV. Mármol $(55 \times 33 \mathrm{~cm}$.), Patrimonio Nacional, Palacio Real de La Granja de San Ildefonso.

través de distintas iniciativas, con la tradición italiana de convertir en piezas de interés público las principales obras de su colección, aumentando así su valor y prestigio. Podemos adivinar su mano en el permiso concedido por Felipe $\mathrm{V}$ en 1744 para la realización de los vaciados de dos piezas emblemáticas de la colección, el Fauno del Cabrito y el Grupo de San Ildefonso, que deberían servir de aprendizaje a los artistas de la incipiente Real Academia de Bellas Artes de San Fernando ${ }^{34}$. Y del mismo modo, y al igual que anteriormente habían hecho otros miembros de la dinastía Farnesio, tras el fallecimiento de Felipe V en 1746 y el traslado de la residencia oficial de la parmesana a La Granja un año después, la reina viuda emprendió un proyecto para ordenar la colección de esculturas, y posteriormente estudiarla y editar una descripción ilustrada de la misma.

33 Para diferenciar la propiedad de las esculturas, las pertenecientes al rey se marcaron con un aspa o cruz de San Andrés y las de la reina con una flor de lis. Recientemente hemos localizado un inventario detallado de las esculturas propiedad de Felipe V en el palacio de La Granja de San Ildefonso fechado en 1748, conservado en el A.G.P., S.I., caja 22.182, fols. 136r-150r. Quiero agradecer la noticia a Rafael Villarreal e Isabel Garzón, del Archivo General de Palacio.

34 Chocarro Bujanda, C., La búsqueda de una identidad. La escultura entre el gremio y la academia (1741-1833), Madrid, 2001, pp. 201-202, y Rodríguez Ruiz, D., "Sobre el "apacible engaño de la vista". Arte y arquitectura en España durante la primera mitad del siglo XVIII", en Santiago Páez, E. (dir.), La Real Biblioteca Pública, 1711-1760. De Felipe V a Fernando VI, Madrid, 2004, p. 97. 
Tras la muerte de Felipe V, el proyecto de Filippo Juvarra de crear una gran galería en el palacio de San Ildefonso que ilustrase la magnificencia y las virtudes del rey a través de distintas pinturas y esculturas quedó abandonado, decidiéndose colocar las estatuas y relieves reunidos por los reyes en las estancias de aparato del cuarto bajo. El primer criterio para la selección de las piezas -almacenadas hasta entonces en la "casa de las alhajas"- fue su buen estado de conservación, como muestra el listado elaborado en julio de 174935 . Tenemos constancia de que en noviembre de dicho año ya estaban colocadas "las musas, i zesares" en la sala de la fuente -conservando la disposición que Cristina de Suecia les dió en el Palacio Riario- y diversas estatuas en otras estancias - probablemente en el orden que muestra el inventario de bienes de la reina redactado en $1766^{36}$, si bien se tuvieron que retirar temporalmente para realizar algunas reparaciones, momento que fue aprovechado para restaurar los pedestales de las esculturas 37 .

Una vez que la galería de estatuas quedó configurada e instalada en 1750 se pudo comenzar con el estudio de la colección. La responsabilidad de llevar a cabo tal empresa, sin precedentes hasta entonces en la corona española ${ }^{38}$, recayó sobre el abate Eutichio Aiello e Liscari. Nacido en Sicilia, el religioso de la orden benedictina llegó a España en 1743 formando parte del séquito de la esposa de Stefano Reggio, príncipe de Jaci, embajador partenopeo en Madrid, y durante su estancia en la corte sabemos que trabajó "por nueve años, en la Real Biblioteca y Museo de San Ildefonso" sirviendo "a una de las mayores reinas que jamás vio la tierra" y al infante don Luis, quien le nombró su teólogo y consultor de cámara hasta 1752, fecha en la que regresó a Italia ${ }^{39}$.

El abate concluyó su trabajo en 1751, por lo que Isabel de Farnesio le recompensó con un pectoral y una sortija "de zafiros y diamante [...] en consideración al trabajo que ha hecho en la descripción de las estatuas de este R[ea] ${ }^{1}$ Palacio" 40 .

Cumpliendo con el encargo regio, Aiello escribió dos manuscritos en italiano. El más extenso, de 224 páginas, que en la actualidad se encuentra desaparecido y del que conocemos su contenido a través del resumen que en 1861 hizo de él Vicens ${ }^{41}$, y el Saggio del Primo Tomo, Il quale contiene la Descrizione di tutte le Divinità, ed Eroi che adornano la Celebre real Galleria di San Yldefonso, localizado en el archivo del Ministerio de Asuntos Exteriores de Madrid por quien esto escribe, y sobre el que preparo una edición crítica ${ }^{42}$.

35 Las obras seleccionadas ascendían a treinta estatuas y cuarenta y tres bustos. A.G.P., S.I., caja 13.578

36 Sobre los distintos cambios de emplazamientos de las esculturas, Herrero Sanz, M. J., "Localización de las esculturas del Palacio Real de La Granja de San Ildefonso según los inventarios reales", Reales Sitios, núm. 144, 2000, pp 14-25; Idem, "Recorrido de la escultura clásica en el Palacio de San Ildefonso a través de los Inventarios Reales", en El coleccionismo de escultura clásica en España, Madrid, 2002, pp. 239-258.

37 A.G.P., S.I., caja 13.582.

38 Sobre la fortuna de la colección real española de escultura, Silva Maroto, P., "La escultura clásica en las colecciones reales: de Felipe II a Felipe V”, en Checa, F. y Schröder, S. (dir.), El coleccionismo de escultura clásica en España, Madrid, 2001, pp. 11-41.

${ }^{39}$ Los escasos datos que conocemos respecto a Eutichio Aiello y Liscari proceden de las Novelle Letterarie pubblicate in Firenze l'anno MDCCLI (Cacciotti, B., ob. cit., pág. 185, nota 190), las cartas que escritas por el abate al infante don Luis en 1769 desde Roma (Epistolario español. Colección de cartas de españoles ilustres antiguos, Biblioteca de autores españoles, Vol. 62, pp. 208-210), y los distintos documentos inéditos incluidos en este trabajo. Dado que en los documentos italianos se alude al siciliano como "Eutichio Aielli" y en los españoles como "Eutichio Ayelo" o "Eutiquio Ayello", hemos elegido la forma italiana de Eutichio Aiello para referirnos al abate.

40 Dichas joyas fueron realizadas por Francisco Sáez, uno de los principales plateros de la corte que trabajó de forma asidua para la Casa Real, y su coste ascendió a "1.028 pesos sencillos y 5/8". Carta del marqués de Scotti a Juan Cascos Villademoros, San Ildefonso, 13 agosto 1751. A.H.N., Estado, leg. 2.745, exp. 6.

41 Vicens y Gil de Tejada, B., "Rápido examen de una descripción manuscrita de la Galería de Escultura del Real Palacio de San Ildefonso", La Razón, 1861, núm. 2, pp. 394-400.

42 M.A.E., Manuscritos, núm. 23. Incluido en el catálogo realizado por don Miguel Santiago Rodríguez (Los manuscritos del archivo general y biblioteca del Ministerio de Asuntos Exteriores, Madrid, 1974, p. 241) esta obra fue puesta 
El Saggio consiste en una guía abreviada que Aiello escribió para la reina, y que debía completarse con un segundo volumen en el que se describiesen las estatuas de "Cleopatra, di Giulio Cesare, d'Augusto, di Livia, di Costantino", y las distintas urnas sepulcrales, bajorrelieves y bustos que se hallaban expuestos en la galería de esculturas del palacio, entre los que destacaban el de "Bruto liberatore di Roma" o los de Alejandro Magno y su madre Olimpia.

Siguiendo el modelo de L'antiquité expliquée et representée en figures de Montfaucon, Aiello organizó su obra en diatribas o capítulos dedicados a las distintas divinidades y personajes de la antigüedad presentes en la colección de esculturas de La Granja. A través de los 25 capítulos de que se compone el Saggio, en los que se describen 63 estatuas, el abate italiano realizó su estudio siguiendo un método basado en los principios de la ciencia anticuaria cuyo fin era "conoscere la vera Persona" que se ocultaba bajo el nombre de las divinidades y personajes del mundo antiguo "per via della Scrittura, e della Storia". Partiendo de esta base, cada una de las diatribas debía comenzar con un análisis del origen mítico de la deidad objeto de estudio y los paralelismos que tuvo en distintas culturas. A continuación se describiría la iconografía de las estatuas de dicha temática, y posteriormente su cronología, las restauraciones que habían sufrido y su autoría. Calificada ésta última por Aiello como "il passo difficilissimo di scoprire sovente il loro Artefice, siasi Greco o Romano", sus atribuciones estaban basadas en la comparación de las obras con otros ejemplares similares y, como sucedía en las colecciones de prestigio, en la presencia en las esculturas de monogramas con la firma del autor o en el hecho de que fueran mencionadas en los textos de los clásicos. Asimismo, para la redacción de su texto Aiello recurrió a "agl'Eruditi d'alto calibro" griegos y latinos, así como italianos, franceses e ingleses a los que, en algunas ocasiones no dudó en desacreditar basándose en los errores que, a su juicio, habían cometido a la hora de explicar los mitos o la iconografía de las estatuas.

El Saggio comienza con la diatriba dedicada a las 14 esculturas de divinidades egipcias que se encontraban expuestas en un espacio diferenciado del palacio, la galería de ídolos ${ }^{43}$. Presentes en las principales colecciones europeas de la época, las obras de arte egipcias o de estilo egiptizante representaban una muestra del atractivo que la cultura faraónica seguía despertando en el siglo XVIII, tanto por el interés y el misterio del lenguaje jeroglífico, interpretado como símbolo de la antigua sabiduría, como por el material en el que estaban realizadas. Si bien al analizar las distintas esculturas Aiello menciona las obras de los principales estudiosos de la cultura egipcia como Athanasius Kircher o Alessandro Maffei, desde esta primera diatriba ya son notorias las carencias del trabajo del abate italiano, tanto en sus conocimientos iconográficos, confundiendo el "ureus" que portaba la estatua II en la cabeza con una flor, como en los aspectos estilísticos, ciñéndose a señalar que las esculturas eran raras, únicas, singulares, "bella e d'un gusto che sorprende", tenían "un non sò che di maestuoso", o simplemente que habían sido realizadas por artífices griegos y romanos.

A partir del segundo capítulo comienza el estudio de las esculturas de las divinidades y héroes de la mitología grecolatina presentes en la galería de estatuas de La Granja de San Ildefonso. Tras describir las de Júpiter, una de las cuales era la que, según Aiello, "Flaminio trasportò di Macedonia in Roma" (estatua XV) ${ }^{44}$, se analiza la representación de un río (estatua XVII) ${ }^{45}$, que

en relación con el trabajo de Aiello durante las investigaciones realizadas con motivo de la exposición El Real Sitio de La Granja de San Ildefonso. Retrato y Escena del Rey, Madrid, 2000. Sobre este tema, Riaza de los Mozos, M. y Simal López, M., "Eutichio Aiello y Liscari, Saggio del primo tomo", en Rodríguez Ruiz, D. (com.), ob. cit., pp. 436-437, y Riaza de los Mozos, M. y Simal López, M., ob. cit., 2000.

43 Por motivos de extensión únicamente indicaré la localización actual de las esculturas descritas en el Saggio. Respecto a los ídolos egipcios, actualmente tan sólo se conservan cinco: M.P., E-415 (estatua IV), E-414 (estatua VI), E-413 (estatua VII); Museo Arqueológico Nacional, deposito del M.P., E- 412 (estatua XI); M.P., E-323 (estatua XII) y E-703 (estatua XIV).

44 M.P., E-5 (estatua XV) y E-16 (estatua XVI).

45 Esta escultura ha sido localizada recientemente por Margarita Estella en los jardines del real palacio de Aranjuez. Estella, M., "El llamado Neptuno (¿Río?) de la colección del Carpio y su problemática identificación con una obra atribuida a Bernini en Aranjuez", Archivo Español de Arte, núm. 298, 2002, pp. 117-128. 
el italiano atribuyó, basándose en el monograma que tenía grabado -y que aún se conserva-, a "Tiberinus Ostiensis" o a Bastiano Torrigiano.

En la cuarta diatriba destaca un puteal en honor a Baco (estatua XVIII) ${ }^{46}$ que el abate atribuyó a "Sauros", espartano que trabajó en el pórtico de Octavia en Roma.

En la quinta, dedicada a los sátiros, sobresalen las esculturas del Fauno del Cabrito (estatua $\mathrm{XXI})^{47}$, descrito como "un prodigio del arte" y atribuido a Praxíteles gracias al supuesto monograma que tenía grabado en la axila -del que en 1909 no quedaba ni rastro y probablemente fuese "una ilusión del abate italiano" $48_{-}$, y el Sátiro en Reposo (estatua XXII) ${ }^{49}$, calificado como "bello a maraviglia" y "stile pare romano". Curiosamente Aiello, que desconocía que el Fauno fue hallado entre 1674 y 1675 en las excavaciones de un antiguo taller de esculturas en Roma, y que tras ser restaurado por Ercole Ferrata ingresó en la colección de Cristina de Suecia ${ }^{50}$, atribuyó el estado inconcluso de la escultura a la costumbre que, según el abate, tenían los artistas griegos más renombrados, consistente en dejar sin terminar alguna parte de la escultura para que, en caso de crítica, pudieran justificarse indicando que la obra estaba sin concluir.

El sexto capítulo versa sobre las cinco esculturas de Venus presentes en la Real Galería de San Ildefonso. Entre ellas, Aiello destacó la Venus saliendo del baño, calificada "d'una beltà cosi rara, che può stare a fronte della Venere dei Medici" (estatua XXIV) ${ }^{51}$, y la Venus del pomo, una "delle più belle che m'a abbia visto nell'Italia" (estatua XXVII) ${ }^{52}$. Respecto a la autoría de las obras, tan sólo atribuyó la primera a Policarmo, mientras que del resto afirmó que son antiguas, "di Greco stile e d'un gusto particolare", y la quinta una copia moderna.

La séptima diatriba está dedicada al grupo de las Musas, conjunto capital de la colección de Cristina de Suecia ${ }^{53}$. Tras exponer las distintas corrientes historiográficas sobre el origen mítico de estas deidades, sorprendentemente el italiano analizó las esculturas de forma conjunta y sumamente escueta. Tras remitir al lector al estudio de Maffei para los aspectos iconográficos, Aiello se limitó a atribuir las esculturas, siguiendo a Vitruvio y a Pausanias, a Cefisódoro, hijo de Praxíteles, y a mencionar que las Musas de La Granja, "le più rare che ci siano state in Grecia e nell'Italia", eran las mismas "che l'Arcontato famoso di Sicione, fece trasportare nel Templo d'Apolline".

El Saggio prosigue con la descripción de un trípode dedicado a Apolo y de una estatua de una sibila (diatriba VIII) ${ }^{54}$, de una "Statua di Cerere antichissima" (diatriba IX) ${ }^{55}$, y de tres representaciones de Hércules (diatriba X) ${ }^{56}$. En este último capítulo Aiello explicó que había querido estudiar con mayor profundidad la figura del semidiós debido a su vinculación con la corona española, por lo que rogaba a Isabel de Farnesio que "se V. R. M. si dasse la pena di leggere questo discorso, trovarà delle cose che recano piacere", remitiéndola a la versión extensa del manuscrito. Respecto a la autoría de las obras, volvemos a encontrar atribuciones a "le maniere del Greco", o de un estilo que "spira un non sò che di fiero".

46 M.P., E-173.

47 M.P., E-29 (estatua XVIII), E-136 (estatua XIX), E-368 (estatua XX) y E-434 (estatua XXIII).

48 Barrón, E., Museo Nacional de Pintura y Escultura. Catálogo de la escultura, Madrid, 1909, p. 44.

49 M.P., E-30.

50 Negrete Plano, A., "El Fauno del Cabrito y su influencia”, Academia, núm. 89, 1999, pp. 57-83.

51 M.P., E-33.

52 M.P., E-65 (estatua XXVII), E-874 (estatua XXV) y M.P., E-31 (estatua XXVI). La descrita en los inventarios de esculturas de Cristina de Suecia como "statua della venere velata, detta trasparente" (estatua XXVIII) aún no la hemos identificado.

53 M.P., E-37, E-38, E-40, E-41, E-61, E-62, E-68 у E-69.

54 M.P., E-32 (estatua XXXVIII).

55 M.P., E-44. (estatua XXXIX).

56 M.P., E-432 (estatua XL), E-101 (estatua XLI) y E-108 (estatua XLII). 
En la XI diatriba se describe la estatua de Palas Atenea ${ }^{57}$, y en la XII se estudian las tres representaciones de Apolo reunidas en La Granja, entre las que se encontraba la figura realizada por Nocchieri para Cristina de Suecia (estatua XLVI) ${ }^{58}$. La descripción de esta escultura, además de ser interesante por la atribución errónea que hizo Aiello a Massimiliano Soldani Benzi, basándose en los distintos trabajos que el florentino había realizado para la reina sueca, es de gran utilidad porque nos informa de que Isabel de Farnesio se ocupó personalmente de la ordenación de la galería de esculturas. En el caso concreto de esta obra, la soberana española quiso reconstruir la estancia de las musas que Cristina de Suecia había reunido en el palacio Riario, motivo por el cual ordenó colocar el Apolo "sopra d'un alta rupe o fonte assistendo alle Muse, como Maestro nella sua Cattedra".

Tras describir una pareja de hermas (diatriba XIII) ${ }^{59}$ el abate italiano prosiguió con los capítulos dedicados a las esculturas de Pomona (diatriba XIV) ${ }^{60}$, Fortuna (diatriba XV) 61 y Diana (diatriba XVI) ${ }^{62}$, para centrarse a continuación en otra de las joyas de la colección, el Grupo de San Ildefonso (diatriba XVII)63. Tras expresar que "il Gruppo di queste due Statue originali, è un opera così eccelente, che fá onore alla venerabile Antichità" y que "spirano un non sò che di respetto al greco lavoro", Aiello incluyó una breve recopilación de las distintas interpretaciones dadas sobre su iconografía. Mientras que Perrier, quien estudió la obra en 1634 cuando aún formaba parte de la colección Ludovisi, afirmaba que era una representación de "due Deci sacrificati per la Patria", y Montfaucon lo interpretaba como "due Lari o Dei Penati”, Aiello afirmó que "i nostri due Giovani sono i figlivoli di Leda”. Esta atribución como Cástor y Pólux, con la que el grupo es conocido en la actualidad, se le dio a las estatuas cuando fueron adquiridas por Cristina de Suecia, y se mantuvo posteriormente en los distintos inventarios redactados durante la estancia de las esculturas en la colección Odescalchi, su traslado a España y los inventarios de bienes del palacio de La Granja, lo que hace pensar que el abate también utilizó estos registros de obras de la colección real para la redacción de su catálogo.

Aiello dedicó los siguientes capítulos a las estatuas de Paris (diatriba XVIII) ${ }^{64}$, Aracne Colofonia (diatriba XIX) ${ }^{65}$ y una vestal (diatriba XX) ${ }^{66}$, en los que continuó describiendo las obras de una manera somera y misteriosa. Así, de una de las esculturas de Paris aseguraba que "la sua beltà è stata tale, che gl'Artefice v'hanno gettato sopra dell'argilla, per tirarne fuora de modelli", mientras que respecto a su iconografía tan sólo anuncia que "se metterà in chiaro quest'Enimma, ch'a dir il vero non è da poco" (estatua LIV) ${ }^{67}$. Al enumerar las distintas interpretaciones iconográficas de la Aracne Colofonia, Aiello nos proporciona una de las escasas noticias que nos han llegado sobre la accesibilidad de la colección, mencionando que la galería de estatuas de La Granja era visitada por "milordi inglesi, molti degl'Ambasciadori ed Uomini Illustri” que de Italia, Francia y Alemania llegaban al Real Sitio "tirati dalla fama e dall'Augusto Nome di V. R. M. ambiziosi solo di conoscervi", como prueban las solicitudes de permisos conservadas en el Archivo General de Palacio.

\footnotetext{
57 M.P., E-24 (estatua XLIII).

58 P.N. 10012583 (estatua XLVI), M.P., E-4 (estatua XLIV) y E-369 (estatua XLV).

59 Sólo hemos podido identificar uno de los grupos escultóricos, conservada en el M.P., E-75 (estatua XLVII).

60 M.P., E-186.

61 M.P., E-20.

62 M.P., E-11.

63 M.P., E-28.

64 M.P., E-224 (estatua LIV) y E-12 (estatua LV).

65 M.P., E-164 (estatua LVI).

66 M.P., E-2 (estatua LVII).

67 M.P., E-224.
} 
La descripción de la galería de estatuas concluye con las diatribas dedicadas a Ganímedes (diatriba XXI) ${ }^{68}$, Flora (diatriba XXII ${ }^{69}$, Narciso -estatua de frecuente presencia en las principales galerías de estatuas europeas, y que sin embargo Aiello calificó como de enorme rareza- (diatriba XXIII) ${ }^{70}$, Endimión (diatriba XXIV) ${ }^{71}$, y "una statua di Clizia unica e singolare" (diatriba XXV), bellísima escultura restaurada por Giulio Cartari que Cristina de Suecia había colocado en el palacio Riario como símbolo de su conversión al catolicismo, y que Aiello definió como "un prodigio dell'arte" 72 .

La descripción "extensa" de la galería de estatuas realizada por Aiello debía completarse en la edición impresa con ilustraciones de las esculturas que integraban la colección. Algunos de los dibujos preparatorios, realizados a lápiz en hojas sueltas, se han conservado en el Museo del Prado y se conocen como "Álbum del Cuaderno de Aiello"73. Si bien su cronología era incierta, la coincidencia de la filigrana del papel sobre el que fueron realizados con el utilizado en la redacción del Saggio permite fecharlos entre 1750 y $1751^{74}$. De autoría anónima, aunque posiblemente obra de algún miembro de la academia de dibujo de la Real Fábrica de Cristales de La Granja de San Ildefonso ${ }^{75}$, son de enorme interés, tanto por su valor historiográfico como por mostrar el estado en que se encontraban las esculturas antes de ingresar en el Museo del Prado, en donde, siguiendo las directrices de la época, se desmontaron las restauraciones barrocas añadidas por Cristina de Suecia ${ }^{76}$.

Cuando Aiello entregó sus textos, Isabel de Farnesio, quien como ya hemos mencionado conocía y poseía en su biblioteca ejemplares de los principales estudios de carácter arqueológico del momento, quedó sumamente decepcionada con el trabajo del italiano, lleno de imprecisiones y de afirmaciones gratuitas, y a pesar de recompensarle generosamente, decidió abandonar la idea de publicar la descripción de la galería de escultura por motivos que explicaremos más adelante.

En 1764 comenzó a fraguarse un nuevo proyecto para difundir la colección de esculturas reunida en el Real Sitio con la propuesta que el marqués de Távara, consiliario de la Real Academia de Bellas Artes de San Fernando, hizo a la Junta Particular para hacer una colección de estampas de las fuentes, jardines y del palacio de San Ildefonso de cara a formar una "colección de monumentos de España" similar a la que poseían otros países europeos. La idea fue muy bien acogida, y tras conseguir el permiso de Isabel de Farnesio para pasar a tomar dibujos de su residencia, en 1765 se pensó en elegir a los profesores que debían realizar los diseños, pero ante las noticias relativas a la existencia de dibujos del palacio realizados durante el reinado de Felipe V con el objetivo de

68 M.P., E-35 (estatua LVIII).

69 Tan sólo hemos podido identificar una de las estatuas de Flora, conservada en el M.P., E-82 (estatua LIX).

70 M.P., E-124 (estatua LXI).

71 M.P., E-84 (estatua LXII).

72 Los distintos fragmentos de la escultura original (estatua LXIII) se conservan en el Museo del Prado (E-22, E698, F-20, F-31, F-51, F-82 y F-85). Respecto al vaciado de la escultura realizado en el siglo XIX y que permite conocer el estado en que la obra llegó a España, Storch de Gracia, J. J., "Clitia”, en Rodríguez Ruiz (com.), ob. cit., pp. 447-448.

73 Elvira Barba, M. A. (com.), El "Cuaderno de Aiello" y las esculturas del Museo del Prado, Madrid, 1999; Riaza de los Mozos, M. y Simal López, M., "Dibujos del "Cuaderno de Aiello”, en Rodríguez Ruiz, D. (com.), ob. cit., pp. 435-436; Riaza de los Mozos, M. y Simal López, M., ob. cit., 2000.

74 Beatrice Cacciotti ya mencionó la existencia de la filigrana del tipo "Lirio de Estrasburgo" en el papel de los dibujos (Cacciotti, B., ob. cit., nota 196). Quiero agradecer a José Manuel Matilla, Conservador del Departamento de Dibujos del Museo del Prado, su amabilidad y las facilidades que me ha brindado para estudiar la filigrana de los dibujos del "Cuaderno de Aiello" de cara a la realización de este estudio.

75 Pastor Rey de Viñas, P., Historia de la Real Fábrica de Cristales de San Ildefonso durante la época de la Ilustración (1727-1810), Madrid, 1994, pp. 183-202.

76 León, P., "La colección de Escultura Clásica del Museo del Prado", en Schröder, S. F., Museo del Prado. Catálogo de la escultura clásica. Vol. I: Los retratos, Madrid, 1993, p. 22. 
darlos a la imprenta - ¿tal vez los realizados para ilustrar la descripción de Aiello?-, se pospuso la decisión hasta recopilar el citado material. Las pesquisas dieron como resultado la noticia de que la viuda del escultor Juan Domingo Olivieri había conservado el grueso de los dibujos, pero tras su muerte fueron vendidos, pudiendo reunirse tan sólo cuatro que representaban distintas estatuas colocadas en los jardines 77 .

El asunto no volvió a plantearse hasta la Junta Particular del 18 de agosto de 1766, ya fallecida Isabel de Farnesio, en la que se encargó la dirección del proyecto a José de Hermosilla, la elaboración de los planos y dibujos del palacio a Juan de Villanueva e Isidro Carnicero, ambos pensionados en Roma, y la ejecución de los dibujos de las esculturas del interior del palacio a Antonio Carnicero. Una vez elegidos los artífices y fijadas las pautas de trabajo, Tiburcio de Aguirre e Ignacio de Hermosilla escribieron al marqués de Grimaldi para que hiciera llegar a Carlos III los deseos de la Academia y obtener el permiso para "levantar los planos y hacer los dibujos dentro y fuera del Palacio", así como "dibujos puntuales de las más insignes estatuas antiguas y de todo lo mejor moderno" que había en el interior ${ }^{78}$. En su carta, ambos especificaban que los dibujos, una vez terminados, debían ser reconocidos y corregidos por Anton[io] Rafael Mengs, garantía última "de la perfección a la que aspiramos". Pero días después Grimaldi les comunicaba la respuesta negativa del monarca, ya que "aunque a S[u] M[ajestad] le ha sido mui grata esta obsequiosa idéa [...] contempla pueda diferirla por ahora, dedicando primero sus loables esfuerzos a los magnificos edificios que cerca y lejos de la Corte publican la antigua perfeccion de la Arquitectura y demas Artes en España, dignos de que el buril los multiplique", eligiéndose La Alhambra de Granada como monumento de estudio.

Esta tajante negativa del soberano hay que ponerla en relación con la decisión tomada por Isabel de Farnesio poco antes de morir, ordenando que tanto los dos manuscritos redactados por Aiello como la carpeta con los dibujos de las esculturas del cuarto bajo del palacio fuesen enviados al archivo de la Primera Secretaría de Estado para evitar que se diese "el caso de que por algún descuido u, otro motivo fuessen copiados, y llegassen a darse a la estampa"79. Gracias a esta orden de la reina sabemos que Carlos VII de Nápoles, y más tarde III de España, había sido uno de los impulsores de que la obra se imprimiese, y quien recomendó al abate a Isabel de Farnesio para la realización de la descripción. Pero finalmente "mudó S[u]. M[ajestad]. enteramente de propósito quando se asseguró de su poco fundamento, assí por las noticias que su elevado R[ea] talento tenía de las estatuas, ídolos, como por la solidez con que rebatieron las opiniones de el $\mathrm{P}[\mathrm{adr}]^{\mathrm{e}}$ muchos estrangeros de distinción que estubieron a ver el sitio a la sazón de residir este religioso en él". De este modo, debido a que Isabel de Farnesio quedó "poco satisfecha de las disertaciones, que [...] havía hecho el P[adr]e Eutiquio Ayello" y por "no querer exponer a la crítica pública la estimación de estos monumentos de la antigüedad"80 la reina dejó pasar la oportunidad de dar a conocer en las cortes europeas la importante colección de esculturas reunidas en el palacio de San Ildefonso, cuyo valor sin embargo era bien conocido por los especialistas, como prueba la correspondencia mantenida entre Mengs y Winckelmann en $1761^{81}$.

77 Rodríguez Ruiz, D., La memoria frágil. José de Hermosilla y las Antigüedades Árabes de España, Madrid, 1992, pp. $80-85$

78 A.S.F., 37-1/, citada en Rodríguez Ruiz, D., ob. cit., 1992, p. 84.

79 Carta del marqués de Gamoneda al marqués de Grimaldi, Madrid, 8 de septiembre de 1766, y respuesta del 16 de septiembre del mismo año. A.G.P., S.I., caja 13.616.

80 A pesar de los intentos de Isabel de Farnesio algunos viajeros utilizaron las reflexiones de Aiello a la hora de describir la galería de esculturas del palacio de San Ildefonso. Prueba de ello es la descripción del religioso Lombardo Norberto Caimo, en la que además de incorporar los datos de Aiello, definió al abate como "un buen aficionado, pero muy circunspecto" y "que no aventuraba jamás su opinión”. García Mercadal, J. Viajes de extranjeros por España y Portugal, Salamanca, 1999, T. IV, pp. 817-818.

81 Winckelmann, J. J., Lettere italiane, Milán, 1961, carta 71, pp. 177-179. Agradezco el conocimiento de esta noticia a María del Carmen Alonso Rodríguez. 
Tras la muerte de Isabel de Farnesio en julio de 1766, el Real Sitio de La Granja cedió definitivamente su preeminencia en favor de Aranjuez. Si bien Carlos III decidió mantener en él las pinturas, esculturas, porcelanas y muebles que habían pertenecido a su madre, años más tarde, y siguiendo la suerte que anteriormente habían corrido otros palacios de la corona que habían dejado de ser frecuentados con asiduidad, el de San Ildefonso fue poco a poco nutriendo de obras de arte a otros sitios reales. En el caso concreto de las esculturas, en 1789 Carlos IV empezó a plantear la posibilidad de utilizar algunas de las estatuas y columnas del palacio segoviano para decorar el recientemente construido Jardín del Príncipe en Aranjuez ${ }^{82}$. Este deseo se materializó en 1791, por lo que a propuesta de Joaquín Dumandre, director de escultura, "fueron extraídos i llevados á Aranjuez i Palacio de esa corte diferentes piezas de columnas, ídolos, estatuas i jarrones que menoscabaron esta colección" 83 .

Si bien el traslado de obras entre los reales sitios era una práctica frecuente, en esta ocasión se encargó "q[u]e se molden y queden exemplares [de las esculturas que se debían trasladar] en los mismos pasages de donde se sacan", para conservar íntegra, aunque fuera a base de copias, la colección reunida por Felipe V e Isabel de Farnesio. Este hecho, excepcional en la historia de la colección real, fue posible gracias a la presencia en la corte de José Pagniucci, formador de la Real Academia de Bellas Artes de San Fernando de Madrid ${ }^{84}$.

El italiano -quien ya conocía la riqueza de la colección de estatuas de La Granja gracias a la visita que había hecho al Real Sitio junto a Antonio Ponz, secretario de la Academia, para documentar su Viaje de España- fue elegido " $p[a r]^{a}$. hacer mejor el buen serv[ici] ${ }^{\circ}$. del Rey y obviar el peligro de cualquiera estracción o comercio q[u]e . pudiera hacer algún moldador particular". De este modo, durante 1791 Pagniucci se encargó de realizar los vaciados de ocho ídolos egipcios, catorce bustos de emperadores, un grupo de niños, y otras tres estatuas pequeñas, por lo que el conserje de La Granja, Facundo María Sani, acordó pagarle por su trabajo -el coste total de los vaciados ascendió a 32.436 reales de vellón- y permitir que la Academia se quedase con los mol$\operatorname{des}^{85}$.

La elección de un miembro de dicha institución para la ejecución de los vaciados se debía, como hemos apuntado, al doble deseo de evitar que se sacaran de forma indiscriminada copias de las esculturas de la colección real que posteriormente podían ser vendidas sin control, y " $\mathrm{p}^{[\mathrm{or}]}$. si acaso necesitasen hacer algún vaciado $\mathrm{p}^{[\text {ara] }}$. estudiar". Asimismo, el trabajo efectuado sentó un precedente, ya que Carlos IV decidió que, a partir de entonces, cada vez que se trasladasen esculturas del palacio de La Granja previamente se hiciera una copia en yeso que debía quedar en el Real Sitio ${ }^{86}$. Además, el monarca permitió que entre 1792 y 1794 Pagniucci realizara los vaciados de otras 57 esculturas del palacio de San Ildefonso, entre las que se encontraban las principales de la colección de Cristina de Suecia. El coste ascendió a 100.000 reales de vellón, y tras ser concluidos los moldes quedaron depositados en la institución madrileña en $1796^{87}$.

82 A.G.P., S.I., caja 13.660 .

83 A.M.P., leg. 11.200 , exp. 15 y A.G.P., Administrativa, leg. 42.

84 Azcue Brea, L., "Los vaciados en la Real Academia de Bellas Artes de San Fernando, la dinastía Pagniucci”, Academia, núm. 73, 1991, pp. 400-427. Además de trabajar para la casa real, también lo hizo para distintos miembros de la alta nobleza española. Sobre sus trabajos para la marquesa de Peñafiel, la duquesa del Infantado o los duques de Osuna, A.H.N., Nobleza, leg. 393, docs. 20-23.

85 A.G.P., S.I., caja 13.668

86 Junta Particular de la Real Academia de Bellas Artes de San Fernando, 2 de octubre de 1791. A.S.F., leg. 33-14/1. Agradezco esta información a José María Luzón.

87 La orden para que se comenzasen a vaciar las esculturas data de 1792 (A.G.P., Administrativa, leg. 42). El listado completo de los moldes se conserva en A.S.F., leg. 33-11/1. El coste de la realización de los vaciados ascendió a 130.000 reales (A.G.P., S.I., caja 13.683), y los gastos de conducción de los moldes a la Academia a 17.245 reales (A.G.P., S.I., caja 13.689).

AEA, LXXIX, 315, JULIO-SEPTIEMBRE, 263-278, 2006, ISSN: 0004-0428 
Gracias a esta iniciativa, la Academia pudo incrementar de forma notoria y con piezas de prestigio su colección de vaciados, fundamentales para el aprendizaje de los alumnos de Bellas Artes en la especialidad de escultura y pintura para quienes, siguiendo las ideas de Mengs, el estudio de las estatuas de la antigüedad era la única vía para entender la belleza de la naturaleza.

Si bien la necesidad de disponer de un adecuado fondo de moldes clásicos en la Academia ya había sido puesta de manifiesto desde la época de la Junta Preparatoria, algunos de cuyos miembros habían llevado a cabo distintas iniciativas en este sentido, como el ya mencionado permiso concedido por el rey en 1744, seguramente solicitado por Olivieri, para realizar los moldes de las estatuas del Grupo de San Ildefonso y del Fauno del cabrito, o las compras de vaciados en Italia realizadas en 1749 , no fue hasta finales de siglo cuando la institución madrileña pudo disponer de vaciados de las principales esculturas de La Granja. Dicho conjunto de yesos, además de la importancia que tuvieron en la época de cara a la formación de los artistas, como demuestra la elección de las principales esculturas de la colección de Cristina de Suecia como tema de los concursos de dibujo de la Academia ${ }^{88}$, han resultado de enorme valor para conocer el estado de las esculturas antes de su ingreso en el Museo del Prado, debido a los daños que sufrieron durante el traslado y a las importantes restauraciones a las que Valeriano Salvatierra sometió a las piezas ${ }^{89}$.

Con la fundación del Museo del Prado en 1819 se produjo el segundo gran traslado de las esculturas de la reina Cristina de Suecia en España. Para dotar al nuevo museo de una colección estatuaria de prestigio, una comisión encabezada por el duque de Híjar, director de la institución y Sumiller de Corps del rey, y Valeriano Salvatierra, escultor de cámara y conservador de la colección estatuaria de la nueva institución, fue la encargada de seleccionar las obras más representativas de los reales sitios.

En el caso de San Ildefonso, en junio de 1827 el primer escultor de cámara José Álvarez, acompañado de su hijo, se trasladó dos días a La Granja para "reconocer todos los efectos de escultura", seleccionando la mayoría de las obras procedentes de la colección de Cristina de Suecia para que, tal y como ya había sugerido Antonio Ponz en 1787, "sirviesen de estudio a los que desean aprovechar en lo mejor, y juntamente de adorno a la capital del reino" 90 . Antes de ser llevadas a Madrid en 1828, al igual que había ocurrido en la época de Carlos IV, se realizaron vaciados en yeso de las esculturas que iban a ser trasladadas -a partir de los moldes obtenidos en la década de 1790 y que custodiaba la Real Academia de Bellas Artes de San Fernando- para mantener el aspecto de las estancias del cuarto bajo del palacio.

Con el paso del tiempo y las distintas modificaciones que se hicieron en la decoración y uso de las estancias del palacio de San Ildefonso, la colección de escultura fue perdiendo su sentido y valor de conjunto, siendo dispersadas las estatuas originales, los pedestales encargados por Cristina de Suecia y los ya mencionados calcos en yeso, que adquirieron a partir de entonces un mero valor decorativo o bien fueron trasladados a los almacenes.

Gracias a los trabajos de restauración llevados a cabo en el Real Sitio de La Granja por Patrimonio Nacional entre 1998 y 2000, el palacio ha recuperado la decoración y el sentido con el que fue concebido en la época de Felipe V e Isabel de Farnesio, y de nuevo el cuarto bajo se muestra al público como la galería de estatuas que antaño fue.

Recibido: 15-III-2005

Aceptado: 12-V-2005

88 AA.VV., Historia y alegoría: los concursos de pintura de la Real Academia de Bellas Artes de San Fernando (1753-1808), Madrid, 1994.

89 A.H.N., Diversos, colecciones, leg. 364, exp. 22.

90 A.G.P., S.I., caja 13.736. Ponz, A. Viaje de España, Madrid, 1947, p. 322. 